\title{
The influence of binder content on the water transport properties of waterborne acrylic paints
}

\author{
Sacide Alsoy Altinkaya*, Ozge Topcuoglu, Yilmaz Yurekli, Devrim Balkose \\ Izmir Institute of Technology, Department of Chemical Engineering Gulbahce Koyu, 35340, Urla Izmir, Turkey
}

\section{A R T I C L E I N F O}

\section{Article history:}

Received 15 February 2010

Received in revised form 5 July 2010

Accepted 10 August 2010

\section{Keywords:}

Waterborne acrylic based paint films

Gravimetric sorption

Water diffusivity

Sorption isotherm

Modeling

\begin{abstract}
A B S T R A C T
Diffusion coefficients and sorption isotherms of water in waterborne acrylic paint films and in the pure binder of the paints have been measured by gravimetric sorption. Solubility of water was found to enhance with the increased binder content in the paint films while the diffusivity of water decreased significantly. Sorption isotherms in the paint and pure copolymer films were correlated with the Flory Huggins theory and ENSIC model, respectively. Fickian diffusion was observed in both types of films and the kinetic data were best correlated with a numerical model which takes into account the concentration dependency of the diffusion coefficient and the dimensional change of the film due to sorption. It was concluded that the utilization of a simplified analytical solution may lead to significant errors in the estimation of diffusivities.
\end{abstract}

(c) 2010 Elsevier B.V. All rights reserved.

\section{Introduction}

Paints are used for both their decorative and protective functions. The quality of the paint is strongly influenced by its water transport properties. Water penetration into the paint leads to growth of fungi and loss of adhesion between the paint and underlying substrate. In addition, water is the main carrier for the penetration of the aggressive ions originating from rain and water soluble gases such as $\mathrm{CO}_{2}$ and $\mathrm{SO}_{2}$ which both cause a negative effect on the protection of the substrate. Thus, measurement of water transport properties in the paint is critical to evaluate its protecting characteristics.

Different experimental techniques have been used in measuring the water transport properties of the paints. The most commonly used technique is electrochemical impedance spectroscopy which is based on following the coating capacitance evaluation as a function of time [1-8]. The data are then related to water uptake from which the diffusion coefficient is calculated by employing the classical solution of Fick's second law. Goossens et al. [9] used the cup method in which the mass flux through a paint film is caused by creating different relative humidities on both sides of the film. To determine the diffusivity of water in the paint, experimentally measured mass flux data were combined with the mathematical expression derived by considering mass transfer through the film and in the air layers around the film as well. The same group has also used an interferometric technique to measure the swelling of

\footnotetext{
* Corresponding author. Tel.: +90 2327506658; fax: +90 2327506645

E-mail address: sacidealsoy@iyte.edu.tr (S.A. Altinkaya).
}

the paint caused by water vapor absorption [10]. The diffusion coefficient of water in the paint was then obtained from the change in the thickness of the film with time within the range of the relative humidity of the air between $50 \%$ and $90 \%$. van der Zanden and Goossens [11] used the sorption method in which the paint film on a substrate was subjected to an atmosphere in a closed vessel and the change in the water concentration in air as a function of time was measured. These data were then compared with the model predictions to determine transport properties of water. Philippe et al. [8] used liquid gravimetric sorption and attenuated total reflection infra-red spectroscopy (ATR-IR) techniques to determine the transport properties of water in the commercial paint coating. In these techniques, the increases in weight and absorbance of the coating as a function of time were followed respectively and in order to calculate the diffusion coefficient of water, these data were evaluated with the mathematical models based on Fick's second law.

The main objective of this study was to measure the water transport properties of waterborne acrylic paints formulated with different binder contents and investigate the influence of the paint formulation on transport properties. Different from the experimental techniques used in previous studies, in this study, gravimetric sorption method was used with a magnetic suspension balance which is one of the most reliable and sensitive apparatus among other gravimetric sorption devices. Sorption isotherms were fitted by the Flory Huggins theory and ENSIC model both of which were also used to predict the extent of clustering and mean cluster size of water molecules. In almost all studies published in the literature, the diffusivity of water in the paint film was assumed to be constant and the swelling of the film due to absorbtion of water was not considered. Depending on the experimental conditions, these 


\begin{tabular}{|c|c|}
\hline \multicolumn{2}{|c|}{ Nomenclature } \\
\hline$a_{w}$ & activity of water vapour \\
\hline$D$ & diffusion coefficient $\left(\mathrm{cm}^{2} / \mathrm{s}\right)$ \\
\hline$D_{o}$ & diffusion coefficient at initial concentration $\left(\mathrm{cm}^{2} / \mathrm{s}\right)$ \\
\hline$G_{w w}$ & cluster integral \\
\hline$J_{1}^{o}$ & $\begin{array}{l}\text { mass diffusion flux of penetrant relative to velocity } \\
\text { of polymer }\left(\mathrm{g} / \mathrm{cm}^{2} \mathrm{~s}\right)\end{array}$ \\
\hline$k_{p}$ & $\begin{array}{l}\text { polymer-penetrant interaction parameter for ENSIC } \\
\text { model }\end{array}$ \\
\hline$k_{S}$ & $\begin{array}{l}\text { mutual penetrant interaction parameter for ENSIC } \\
\text { model }\end{array}$ \\
\hline$L$ & initial thickness of the film (cm) \\
\hline$P_{\text {eff }}$ & effective permeability ( $\mathrm{mol} / \mathrm{s} \mathrm{cm} \mathrm{kPa)}$ \\
\hline$q_{1}$ & concentration variable $\left(\mathrm{g} / \mathrm{cm}^{3}\right)$ \\
\hline$q_{1 E}$ & $\begin{array}{l}\text { equilibrium concentration variable of solvent } \\
\left(\mathrm{g} / \mathrm{cm}^{3}\right)\end{array}$ \\
\hline$q_{10}$ & initial concentration variable of the solvent $\left(\mathrm{g} / \mathrm{cm}^{3}\right)$ \\
\hline$t$ & time $(\mathrm{s})$ \\
\hline$x$ & coordinate in the direction of flux (m) \\
\hline$v_{1}$ & mass average velocity of solvent $(\mathrm{cm} / \mathrm{s})$ \\
\hline$v_{2}$ & mass average velocity of polymer $(\mathrm{cm} / \mathrm{s})$ \\
\hline$V_{w}$ & partial molar volume of the water $\left(\mathrm{cm}^{3} / \mathrm{mol}\right)$ \\
\hline$V_{2}$ & specific volume of the polymer $\left(\mathrm{cm}^{3} / \mathrm{g}\right)$ \\
\hline$w_{1}$ & weight fraction of the water \\
\hline$w_{1 o}$ & initial weight fraction of the water \\
\hline$\chi$ & Flory-Huggins interaction parameter \\
\hline & volume fraction of water in the film \\
\hline$\rho_{1}$ & mass density of the water $\left(\mathrm{g} / \mathrm{cm}^{3}\right)$ \\
\hline$\rho_{2 o}$ & initial mass density of the polymer $\left(\mathrm{g} / \mathrm{cm}^{3}\right)$ \\
\hline$\alpha$ & $\begin{array}{l}\text { exponential constant used in defining concentration } \\
\text { dependence of diffusion coefficient }\end{array}$ \\
\hline
\end{tabular}

assumptions may lead to inaccuracies in the determination of diffusion coefficients. In this study, the experimental uptake curves were evaluated with a reliable mathematical model developed by Alsoy and Duda [12] which takes into account both swelling of the film and the concentration dependency of the diffusion coefficient.

\section{Materials and methods}

\subsection{Materials}

Waterborne acrylic based paints that could be applied both on the interior or exterior walls of buildings and containing different amounts (40\%, 30\%, $20 \%$ and $10 \%$ ) of methylmethacrylateco-butylacrylate copolymer as a binder, calcite as a filler and titania as a pigment were prepared by Akril Kimya A.S. The binder was produced and supplied by Organik Kimya A.S. in the form of an emulsion consisting of $50 \%$ copolymer and $50 \%$ water by volume.

\subsection{Film preparation and characterization}

Paint and pure copolymer films were prepared by casting the suspensions on a clean and smooth glass substrate through an automatic film applicator (Sheen Instruments Ltd., model number $1133 \mathrm{~N}$ ). The thicknesses of the cast films were adjusted by using an applicator with the gap sizes ranging from 30 to $300 \mu \mathrm{m}$. Wet films were initially dried in a vacuum oven for a period of $1 \mathrm{~h}$ at $100^{\circ} \mathrm{C}$. They were then easily removed from the glass substrate by immersing the samples in a water bath for a certain period of time ranging from $30 \mathrm{~s}$ to $37 \mathrm{~min}$. To remove residual water, the films were redried in the vacuum oven for 3 days at a temperature of $100^{\circ} \mathrm{C}$. The films were characterized by scanning electron
Table 1

Surface composition of the opaque side of the films.

\begin{tabular}{llllllrr}
\hline \% wet binder & $\mathrm{C}$ & $\mathrm{Na}_{2} \mathrm{O}$ & $\mathrm{MgO}$ & $\mathrm{Al}_{2} \mathrm{O}_{3}$ & \multicolumn{1}{c}{$\mathrm{SiO}_{2}$} & \multicolumn{1}{c}{$\mathrm{CaO}$} & \multicolumn{1}{c}{$\mathrm{TiO}_{2}$} \\
\hline 10 & 34.09 & 1.54 & 2.77 & 3.59 & 14.94 & 16.68 & 26.40 \\
20 & 60.40 & 1.37 & 2.69 & 2.74 & 10.27 & 8.74 & 13.79 \\
30 & 65.05 & 1.57 & 2.71 & 2.99 & 11.72 & 6.85 & 9.11 \\
40 & 70.25 & 1.32 & 2.09 & 2.64 & 9.58 & 5.28 & 8.85 \\
\hline
\end{tabular}

microscopy, EDX analysis, FTIR spectroscopy, thermal gravimetric analysis, X-ray diffraction and their properties were published in our previous article [13]. The copolymer amount in the paint suspensions and in dry paint films are reported as weight \% in Table 1.

\subsection{Experimental setup and procedure}

Fig. 1 shows a schematic of the experimental set up which consists of three main parts: a sorption column, a control unit and a solvent delivery system. During a typical experiment, small pieces of paint films were placed inside a multi-tray sample holder consisting of five trays and the holder was suspended from a permanent magnet in a thermally insulated sorption chamber. Constant temperature in the column was maintained using a double tube thermostat (accuracy: $\pm 0.5^{\circ} \mathrm{C}$ ). Prior to experiments, the column was heated up to $60^{\circ} \mathrm{C}$ and vacuum was applied to remove residual water in the paint films for a period of at least $24 \mathrm{~h}$. Water vapor was prepared in a flask placed into a constant temperature bath (accuracy: $\pm 0.5^{\circ} \mathrm{C}$ ) and its vapor pressure was measured by a pressure transducer (Omega DPG1000B-15A accuracy: 0.25\% full scale) operating within a range of vacuum up to $1 \mathrm{~atm}$. The weight gain in the sample was recorded as a function of time until equilibrium was reached. For the next experimental runs, the vapor pressure of the water was increased incrementally until the temperature in the flask reached $5^{\circ} \mathrm{C}$ below the temperature of the column.

\section{Theory}

\subsection{Modeling of sorption process}

During the sorption process, the paint film with a thickness of $L$ is placed into the multi-tray sample holder in which one side of the film is exposed to the water vapour and the other side is on the impermeable wall of the sample holder. The paint has a complex structure containing many functional ingredients: binder, calcite and titania, and pore formation occurs especially in the paint films including low binder content due to insufficient wetting of the pigments by the binder. However, for the treatment of sorption data the paint structure is assumed to be homogeneous and considered as a pseudobinary system consisting of the paint film and water. Mass transfer in the film is assumed to be one dimensional, driven only by concentration difference and diffusion is Fickian type. One of the most commonly used approach in describing solute transport through the porous media is continuum approach which considers porous medium as a uniform material. In that case, the diffusion of solutes is characterized by the effective diffusion coefficient inside the pores. This coefficient is related to the diffusion coefficient of the same solutes in solutions, the available volume fraction of the solutes, hydrodynamic effects, the binding of the solutes to pore surfaces, and the tortuosity of pathways for diffusion [14]. Furthermore, it is assumed in the model that there is no chemical reaction between the paint film and water. Most of the previous diffusion models additionally assume that diffusion coefficient of the penetrant is constant and the film does not swell due to sorption. In this study, we have adopted a mathematical model derived by Alsoy and Duda [12] which takes into account the swelling of the film, diffusion-induced convection and concentration depen- 


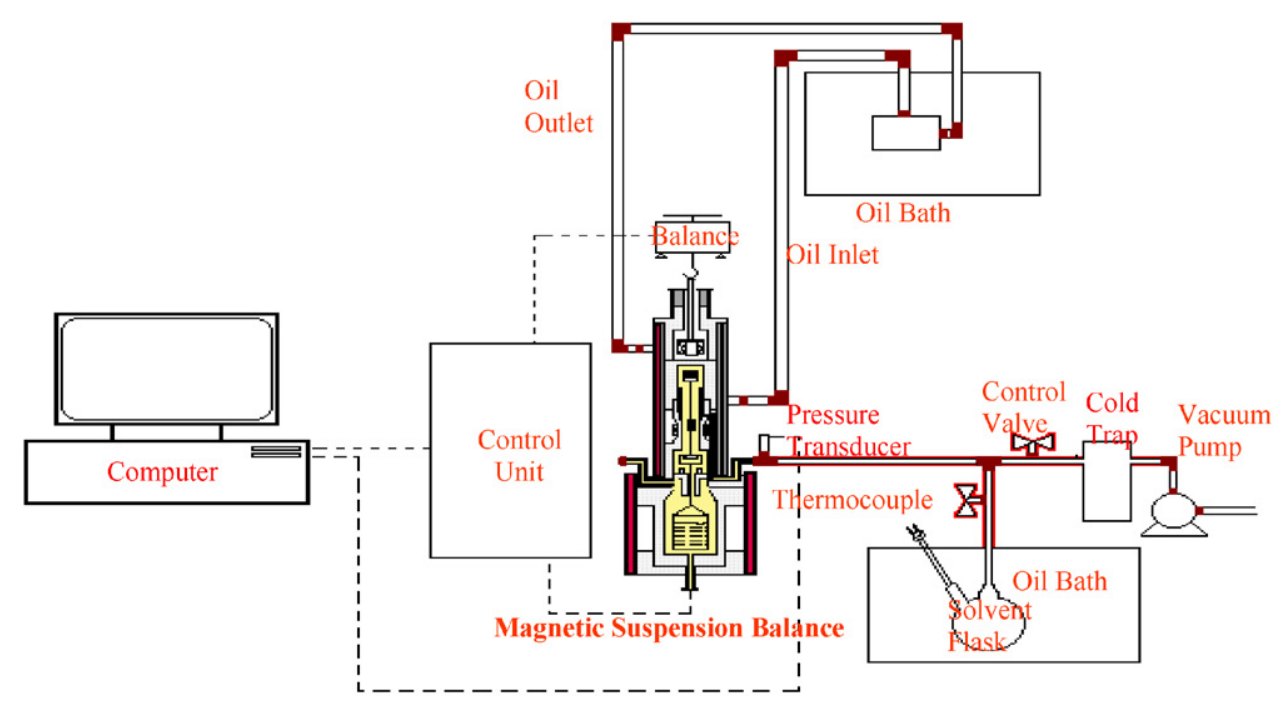

Fig. 1. The gravimetric sorption apparatus

dent diffusion coefficient in the film. According to their formulation, the species continuity equations for the solvent denoted by 1 and polymer denoted by 2 .

$\frac{\partial \rho_{1}}{\partial t}+\frac{\partial\left(\rho_{1} v_{1}\right)}{\partial x}=0$

$\frac{\partial \rho_{2}}{\partial t}+\frac{\partial\left(\rho_{2} v_{2}\right)}{\partial x}=0$

are converted to the following equation:

$\left(\frac{\partial q_{1}}{\partial t}\right)_{\xi}+\left(\frac{\partial J_{1}^{o}}{\partial \xi}\right)_{t}=0$

after introducing a diffusive flux $J_{1}^{o}=\rho_{1}\left(v_{1}-v_{2}\right)$, a new concentration variable, $q_{1}=\rho_{1} / \rho_{2} V_{2}$, and a new length variable $\xi(x, t)=$ $\int_{0}^{x} \rho_{2} V_{2} d x$. If diffusive flux is expressed in terms of new length and concentration variables,

$J_{1}^{o}=D\left(\rho_{2} V_{2}\right)^{2}$

and is substituted into Eq.(3), then the sorption process is described by the following equation:

$\left(\frac{\partial q_{1}}{\partial t}\right)_{\xi}=\frac{\partial}{\partial \xi}\left[D\left(\rho_{2} V_{2}\right)^{2} \frac{\partial q_{1}}{\partial \xi}\right]$

Eq. (5) is a nonlinear equation which is subject to the following initial and boundary conditions:

$\left(\frac{\partial q_{1}}{\partial \xi}\right)_{\xi=0}=0, \quad q_{1}\left(\xi_{L}, t\right)=q_{1 E}, \quad q_{1}(\xi, 0)=q_{1 o}, \quad \xi_{L}=\rho_{2 o} V_{2} L$

In systems involving polymers, concentration dependence of the diffusivities is usually described by an exponential function, therefore, following expression is proposed to be used in Eq. (5):

$D=D_{o} \exp \left[\alpha q_{1}^{*}\right]$

where

$q_{1}^{*}=\frac{q_{1}-q_{10}}{q_{1 E}-q_{10}}$

and the exponent $\alpha$ is allowed to vary with concentration as follows:

$\alpha=\alpha_{1} \exp \left[\alpha_{2}\left(w_{1}-w_{10}\right)\right]$
Experimentally, weight gain in the sample, $M_{I}$, is recorded as a function of time until equilibrium is reached. To determine this quantity theoretically, the concentration $q_{1}$ is integrated over the thickness of the film

$M_{I}=\int_{0}^{\xi_{L}}\left(q_{1}-q_{10}\right) d \xi$

and the equilibrium weight gain in the sample, $M_{I \infty}$, is given by the following expression.

$M_{I \infty}=\xi_{L}\left(q_{1 E}-q_{1 o}\right)$

Experimental uptake data presented as the ratio of amount of water absorbed at any time to the amount absorbed at equilibrium was evaluated with the model predictions from Eqs. (10) and (11) to determine the two diffusion constants $\alpha_{1}$ and $\alpha_{2}$. When $\alpha=0$, then the diffusivity becomes constant $\left(D=D_{0}\right)$.

In cases where swelling of the polymer film is neglected and the diffusion coefficient is assumed to be constant, sorption process is described by the Fick's second law. A solution of Fick's second law along with one initial and two boundary conditions is presented in a classical book of Crank [15]. According to this solution, the mass uptake is defined by the following equation:

$\frac{M_{I}}{M_{I \infty}}=1-\frac{8}{\pi^{2}} \sum_{m=0}^{\infty} \frac{1}{(2 m+1)^{2}} \exp \left\{-D(2 m+1)^{2} \pi^{2} \frac{t}{L^{2}}\right\}$

Crank has shown that at short times as $t \rightarrow 0$, Eq. (12) can be simplified as follows:

$\frac{M_{I}}{M_{I \infty}}=\frac{2}{\sqrt{\pi}}\left(\frac{D t}{L^{2}}\right)^{1 / 2}$

which indicates that mass change curve initially becomes linear. According to Eq. (13), the pre-exponential constant $D_{o}$ in Eq. (7) which corresponds to constant diffusivity was obtained from the initial slope of the $M_{I} / M_{I \infty}$ versus $\sqrt{t}$ graph.

\subsection{Modeling of equilibrium isotherm}

The Flory-Huggins thermodynamic theory is used for correlating the water sorption isotherms [16-18]. Barrie [16] notes that the theory is useful for describing water sorption behaviour in hydrophobic polymers. Perrin et al. [17] showed that the water sorption isotherm in hydrophilic cellulose acetate can be well described by the Flory-Huggins theory for activities less than 0.7 . 


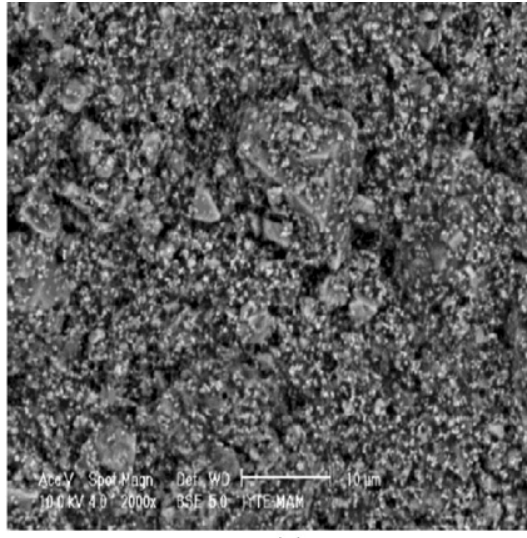

(a)

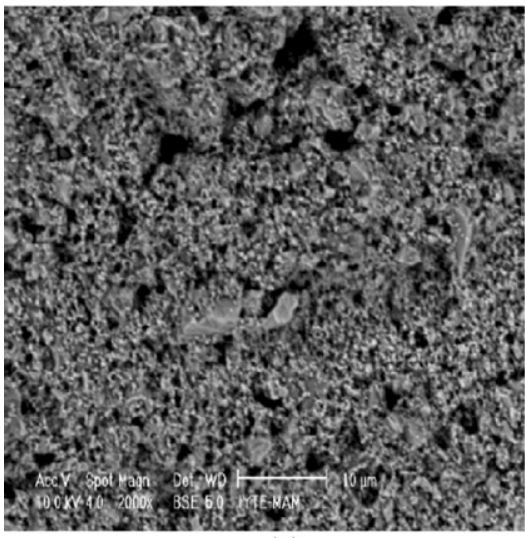

(c)

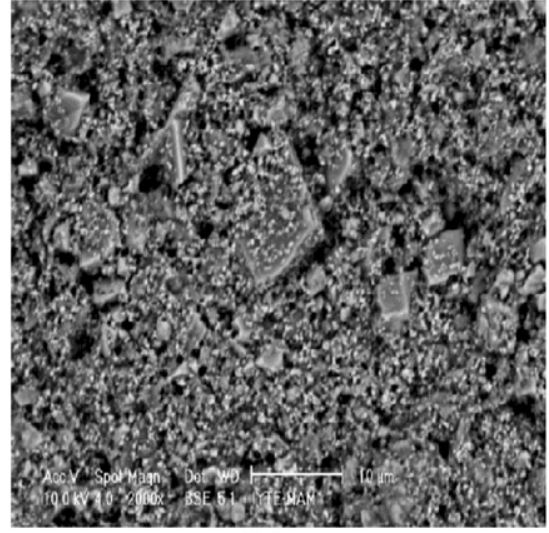

(b)

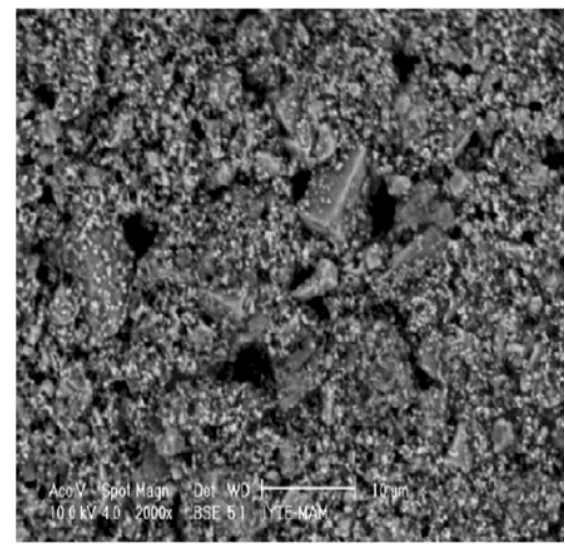

(d)

Fig. 2. SEM micrographs of the opaque surface of the films taken by backscattering: (a) $40 \%$, (b) $30 \%$, (c) $20 \%$, (d) $10 \%$ binder.

According to the Flory-Huggins theory, the relation between activity of water vapour, $a_{w}$, and its volume fraction in the polymer, $\phi_{w}$ is given as follows [19].

$\ln a_{w}=\ln \varphi_{w}+\left(1-\varphi_{w}\right)+\chi\left(1-\varphi_{w}\right)^{2}$

In this expression, $\chi$ represents the Flory-Huggins interaction parameter which provides how much a penetrant can dissolve the polymer. If $\chi$ value is less than 0.5 , then the penetrant is a good solvent for the polymer.

The deviation from the Flory-Huggins thermodynamic theory especially at high penetrant activities lead to another approach derived by Perrin et al. [17]. This model called the ENSIC model takes into account both penetrant-polymer and penetrant-penetrant interactions by introducing a second parameter, $k_{s}$ for mutual penetrant interactions. The interactions between the polymer and penetrant are reflected by the parameter $k_{p}$, which is comparable to the Flory-Huggins interaction parameter $\chi . k_{s}$ and $k_{p}$ are related to the penetrant volume fraction in the polymer by the following equation:

$\varphi_{w}=\frac{\exp \left[\left(k_{s}-k_{p}\right) a_{w}\right]-1}{\left(k_{s}-k_{p}\right) / k_{p}}$

The thermodynamic theories can also be used to determine extent of clustering. Water is a unique penetrant due to its polar nature, thus, it can hydrogen bond with itself and can form clusters. Zimm and Lundberg describe a mathematical approach to determine the extent of clustering based on a cluster integral, $G_{w w}$, which can be calculated from the equilibrium sorption isotherm as follows
[17]:

$\frac{G_{w w}}{V_{w}}=\left(1-\varphi_{w}\right)\left[\frac{\partial\left(a_{w} / \varphi_{w}\right)}{\partial a_{w}}\right]_{P, T}-1$

where $V_{w}$ is the partial molar volume of the water. The quantity $G_{w w} / V_{w}$ indicates whether clustering takes place or not. If $G_{w w} / V_{w}=-1$, the solution is ideal, indicating that water molecules do not affect the distribution of other water molecules. When $G_{w w} / V_{w}$ is between -1 and 0 , clustering is not sufficient yet to overcome the excluding effect of water molecules while at $G_{w w} / V_{w}=0$ excluding effect of the water molecules is balanced by the clustering effect. At the other limits, if $G_{w w} / V_{w}>0$, water molecules tend to cluster, whereas if $G_{w w} / V_{w}<-1$, the water molecules prefer to remain isolated [17].

\section{Results and discussion}

\subsection{Morphology, composition and properties of the films}

The morphology of the surfaces of the films are shown in Fig. 2. Very small copolymer particles are dispersed on the surface of the inorganic particles with a broad range of distribution. There were empty spaces between the particles forming the films. The EDX analysis of the surface films reported in Table 1 showed that surface of the films is very rich in $\mathrm{C}$ content coming from binder particles. $\mathrm{X}$-ray diffraction showed calcite and titania are present in the films. TGA analysis showed a two step mass loss starting around 250 and $600^{\circ} \mathrm{C}$ due to degradation of organic components and decomposition of calcite to $\mathrm{CaO}$ and $\mathrm{CO}_{2}$ [13]. The binder content calculated 
Table 2

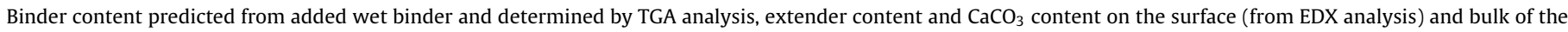
films (from TGA analysis), \% ash by TGA analysis.

\begin{tabular}{|c|c|c|c|c|c|c|}
\hline$\%$ wet binder & $\begin{array}{l}\% \text { dried binder } \\
(\mathrm{C}, \mathrm{H} \text { and } \mathrm{O}) \\
\text { predicted }\end{array}$ & $\begin{array}{l}\text { \% dried binder } \\
(\mathrm{C}, \mathrm{H} \text { and } \mathrm{O}) \\
\text { TGA }\end{array}$ & $\%$ dried extender & $\begin{array}{l}\% \mathrm{CaCO}_{3} \\
\text { surface, } \mathrm{EDX}\end{array}$ & $\begin{array}{l}\% \mathrm{CaCO}_{3} \text { bulk, } \\
\text { TGA }\end{array}$ & $\%$ ash \\
\hline 10 & 5 & 9.21 & 4.21 & 13.10 & 56.56 & 65.12 \\
\hline 20 & 10 & 15.38 & 5.38 & 6.86 & 55.65 & 60.18 \\
\hline 30 & 15 & 21.22 & 6.22 & 5.38 & 55.65 & 43.67 \\
\hline 40 & 20 & 26.36 & 6.36 & 4.15 & 55.65 & 45.71 \\
\hline
\end{tabular}

Table 3

Maximum solubility of water in films (\% volume), water vapour permeability and effective diffusion coefficient of water vapor in paint and copolymer films.

\begin{tabular}{|c|c|c|c|}
\hline Binder \% weight in suspensions & $\begin{array}{l}\text { Maximum solubility of water } \\
\text { in films \% volume }\end{array}$ & $P_{\text {eff }}\left(\times 10^{12} \mathrm{~mol} / \mathrm{s} \mathrm{cm} \mathrm{kPa}\right)^{\mathrm{a}}$ & $D_{i}\left(\times 10^{7} \mathrm{~cm}^{2} / \mathrm{s}\right)^{\mathrm{b}}$ \\
\hline 10 & 3.30 & 26.97 & 46.3 \\
\hline 20 & 5.28 & 13.65 & 34.1 \\
\hline 30 & 6.40 & 1.69 & 1.47 \\
\hline 40 & 6.40 & 0.78 & 0.45 \\
\hline 100 & 6.43 & 0.73 & 1.24 \\
\hline
\end{tabular}

a From Ref. [13].

b Effective diffusivity of water vapor in initially dried films.

from added amount and determined from TGA were different from each other as reported in Table 2, indicating that there was around $5 \%$ weight organic extender in the paint films. In Table 3 water solubility, effective water vapour permeability and effective diffusion coefficient of water in the films are shown.

\subsection{Sorption isotherms}

Equilibrium sorption isotherms of water in the paint films were measured at $30^{\circ} \mathrm{C}$ and plotted as the activity of water vapor against its volume fraction in the film. The activity was calculated from the ratio of vapor pressures of the water at the temperatures in the solvent flask and the column, respectively. The results shown in Fig. 3 indicate that water sorption capacity of the paint films decreases with the decreased binder content in the films. This occurs since the lower the binder content of the films is, the higher is the concentration of the fillers and pigments which are insoluble dense inorganic substances. The equilibrium isotherms in Fig. 3 were successfully fitted by the Flory-Huggins thermodynamic theory.
The Flory-Huggins interaction parameters, $\chi$, for the paint films with the binder contents of $40 \%, 30 \%, 20 \%$ and $10 \%$ were found as $2.07,2.07,2.36$ and 2.61 , respectively by minimizing the difference between the experimental data and the predictions from Eq. (14). All of the interaction parameters are greater than 0.5 indicating that water cannot completely dissolve the paint films. Maximum water sorption capacity of the films, corresponding to activity equals to one, cannot be determined experimentally due to condensation risk in the column when the temperature of the water vapour is equal to the temperature of the column. On the other hand, by utilizing the Flory-Huggins thermodynamic theory these values were predicted as seen in Table 3. During paint formulation, the decrease in the binder content is compensated by the increased pigment amount. This has been shown in our previous work in which average weight percent of the elements present in the paint films were determined with the energy dispersive X-ray (EDX) analysis [13]. Pigments are generally insoluble dense substances, thus, the decrease of water solubility in the films is expected with the increased fraction of the pigment.

Table 4

Effective diffusivity data for water-paint systems at $T=30^{\circ} \mathrm{C}$ and water-pure copolymer system at $T=30$ and $40{ }^{\circ} \mathrm{C}$.

\begin{tabular}{|c|c|c|c|c|c|c|c|}
\hline$\%$ binder & Temperature $\left({ }^{\circ} \mathrm{C}\right)$ & $L_{\text {initial }}(\mu \mathrm{m})$ & $P_{\text {solvent }}(\mathrm{Pa})$ & $\omega_{10}$ & $\omega_{1 E}$ & $\omega_{\text {Average }}{ }^{\mathrm{a}}$ & $D\left(\times 10^{7} \mathrm{~cm}^{2} / \mathrm{s}\right)$ \\
\hline \multirow[t]{9}{*}{100} & 30 & 80.0 & 2040 & 0.000 & 0.007 & 0.005 & 1.24 \\
\hline & & 80.6 & 2620 & 0.007 & 0.010 & 0.009 & 3.00 \\
\hline & & 82.1 & 3500 & 0.016 & 0.029 & 0.025 & 2.69 \\
\hline & 40 & 80.0 & 2040 & 0.000 & 0.003 & 0.002 & 4.68 \\
\hline & & 80.3 & 2620 & 0.003 & 0.005 & 0.004 & 4.93 \\
\hline & & 80.4 & 3160 & 0.005 & 0.006 & 0.005 & 8.50 \\
\hline & & 80.5 & 3640 & 0.006 & 0.008 & 0.007 & 5.44 \\
\hline & & 80.7 & 4120 & 0.008 & 0.013 & 0.012 & 4.80 \\
\hline & & 81.1 & 5200 & 0.013 & 0.027 & 0.023 & 3.82 \\
\hline \multirow[t]{3}{*}{40} & 30 & 37.3 & 2075 & 0.000 & 0.013 & 0.009 & 0.45 \\
\hline & & 38.3 & 2500 & 0.013 & 0.016 & 0.014 & 1.50 \\
\hline & & 38.5 & 3500 & 0.016 & 0.024 & 0.021 & 2.90 \\
\hline \multirow[t]{3}{*}{30} & 30 & 66.0 & 2280 & 0.000 & 0.014 & 0.009 & 1.47 \\
\hline & & 68.0 & 2860 & 0.014 & 0.018 & 0.017 & 1.99 \\
\hline & & 69.0 & 3260 & 0.018 & 0.021 & 0.019 & 10.0 \\
\hline \multirow[t]{4}{*}{20} & 30 & 121 & 580 & 0.000 & 0.006 & 0.004 & 34.1 \\
\hline & & 122 & 1630 & 0.006 & 0.009 & 0.009 & 26.9 \\
\hline & & 123 & 2500 & 0.009 & 0.013 & 0.012 & 21.3 \\
\hline & & 124 & 3000 & 0.013 & 0.017 & 0.015 & 19.2 \\
\hline \multirow[t]{3}{*}{10} & 30 & 130 & 1970 & 0.000 & 0.009 & 0.006 & 46.3 \\
\hline & & 132 & 2400 & 0.009 & 0.01 & 0.010 & 21.6 \\
\hline & & 133 & 2950 & 0.010 & 0.013 & 0.012 & 12.7 \\
\hline
\end{tabular}

${ }^{\mathrm{a}} \omega_{\text {Average }}=\omega_{10}+0.7\left(\omega_{1 E}-\omega_{10}\right)$. 


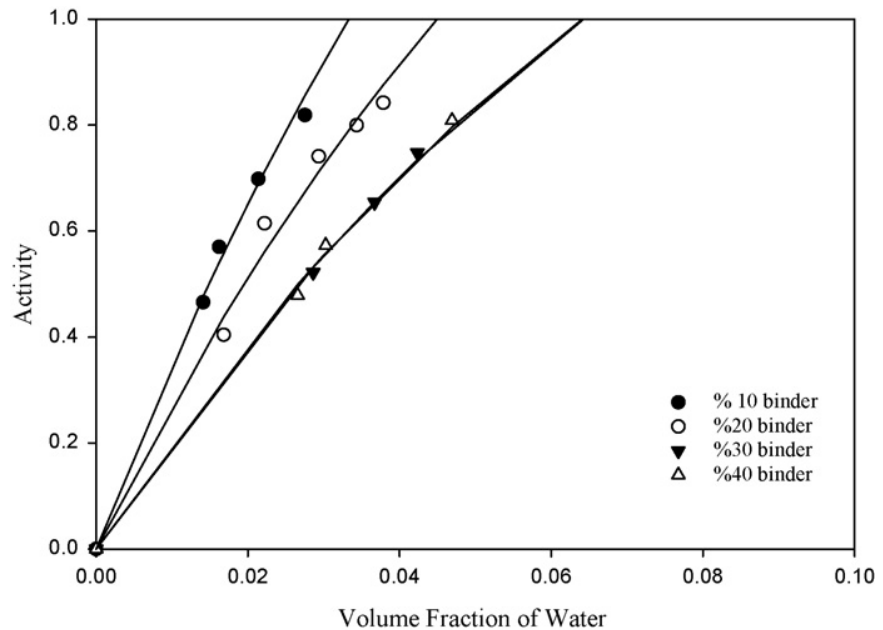

Fig. 3. Equilibrium sorption data for water/paint systems at $30^{\circ} \mathrm{C}$. The symbols and solid lines represent experimental data and correlations using the Flory Huggins model (Eq. (14)).

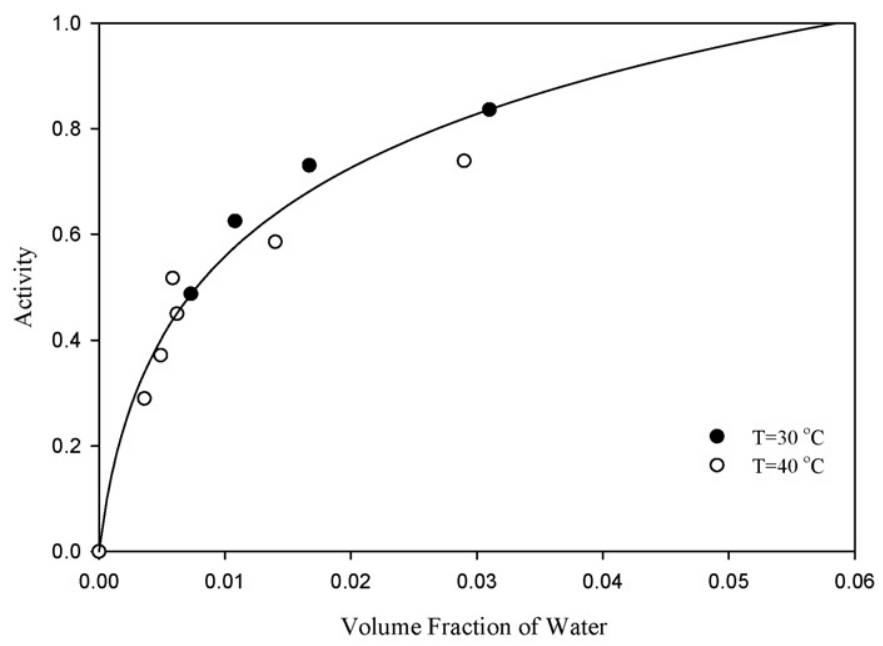

Fig. 4. Equilibrium sorption data for water/pure copolymer system. The symbols and solid line represent experimental data and correlation using ENSIC model (Eq. (15)).

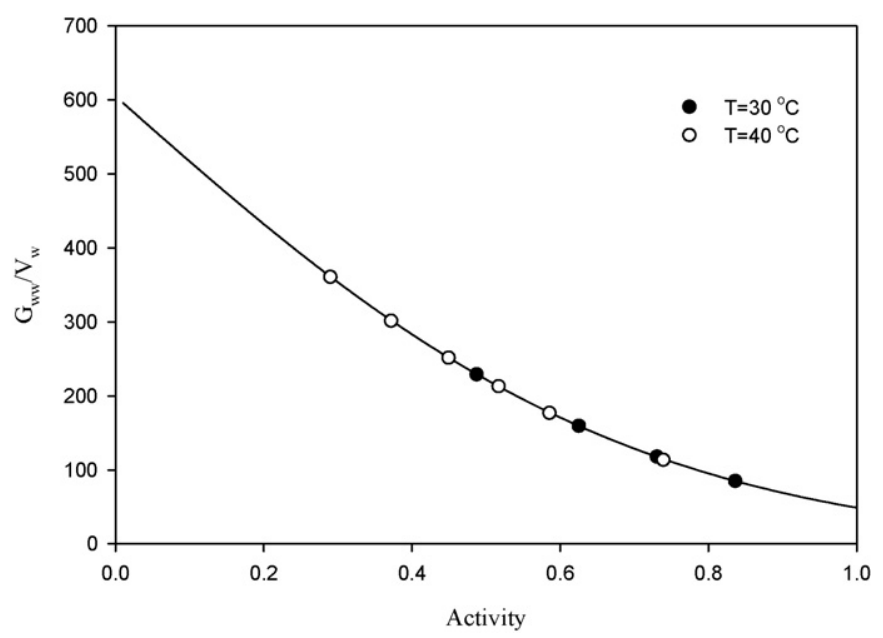

Fig. 5. The change of clustering function with respect to water vapor activity for pure copolymer film.

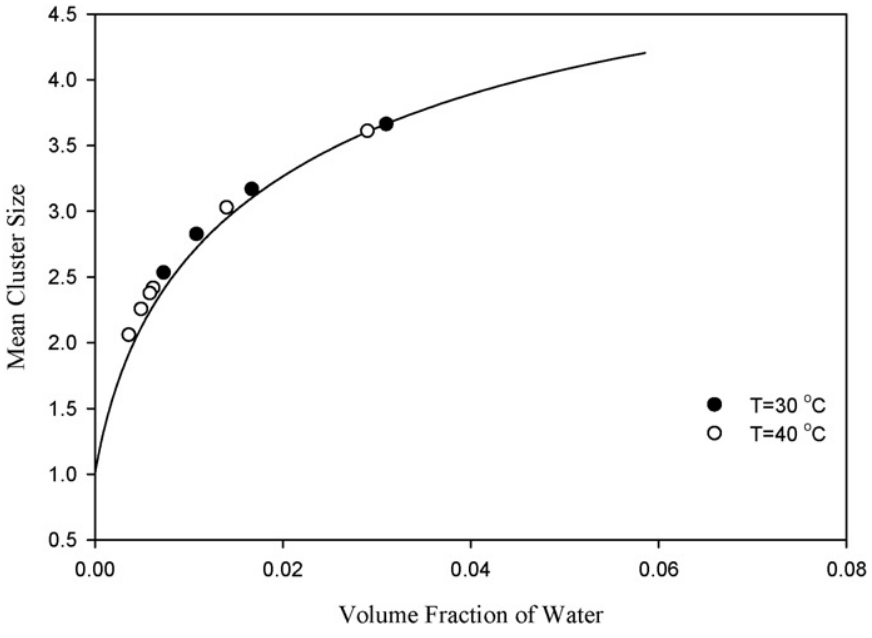

Fig. 6. The change of mean cluster size with respect to volume fraction of water for pure copolymer film.

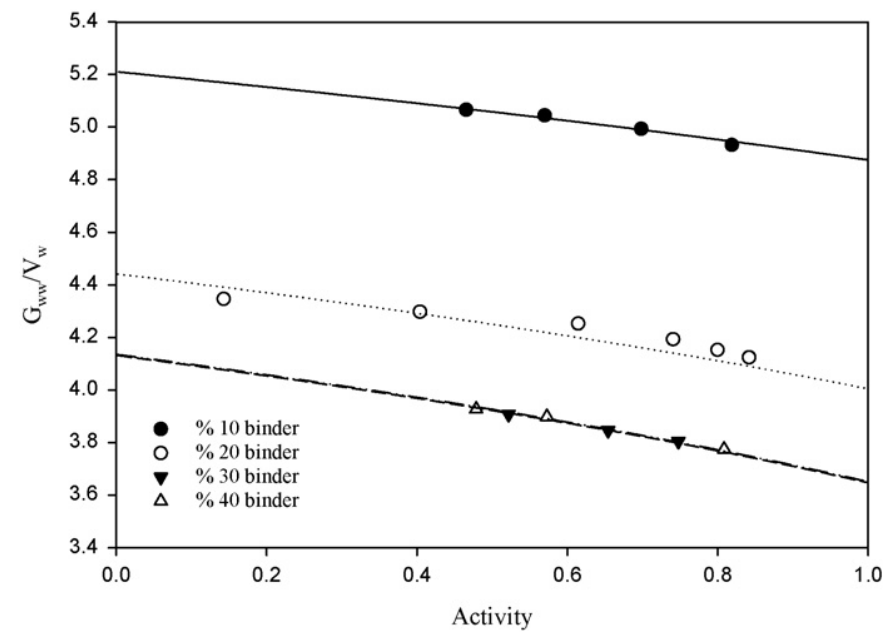

Fig. 7. The change of clustering function with respect to water vapor activity for paint films at $30^{\circ} \mathrm{C}$.

Water vapour sorption equilibrium data in the pure copolymer are shown in Fig. 4. It was found that the sorption isotherm for the pure copolymer does not obey the Flory-Huggins theory over the whole water activity range. At high water activities, the water sorption increases faster than that predicted by the FloryHuggins theory. The isotherm over the whole activity range was fitted well by the ENSIC model which takes into account the possibility of cluster formation. Using the sorption data at 30 and $40^{\circ} \mathrm{C}$ temperatures, two parameters of the model were determined as $k_{s}=4.372$ and $k_{p}=0.00361$. Based on these values the maximum water sorption capacity of the pure copolymer was predicted as $6.43 \%$ slightly higher than the water sorption capacity of the paint films with the binder contents of $40 \%$ and $30 \%$. A significant degree of upturn in sorption data at high activities can be due to clustering of water molecules or plasticization of the polymer matrix induced by water sorption [20]. The extent of clustering of water molecules inside the polymer matrix was determined from the Zimm and Lundberg cluster integral [18]. Fig. 5 shows the clustering function, $G_{w w} / V_{w}$, found from Eq. (16) as a function of water vapour activity for the pure copolymer film. For all water activities, $G_{w w} / V_{w}$, values are much greater than zero indicating that water molecules tend to cluster. Fig. 6 shows the variation of mean cluster size (MCS) as a function of the volume fraction of water in the 


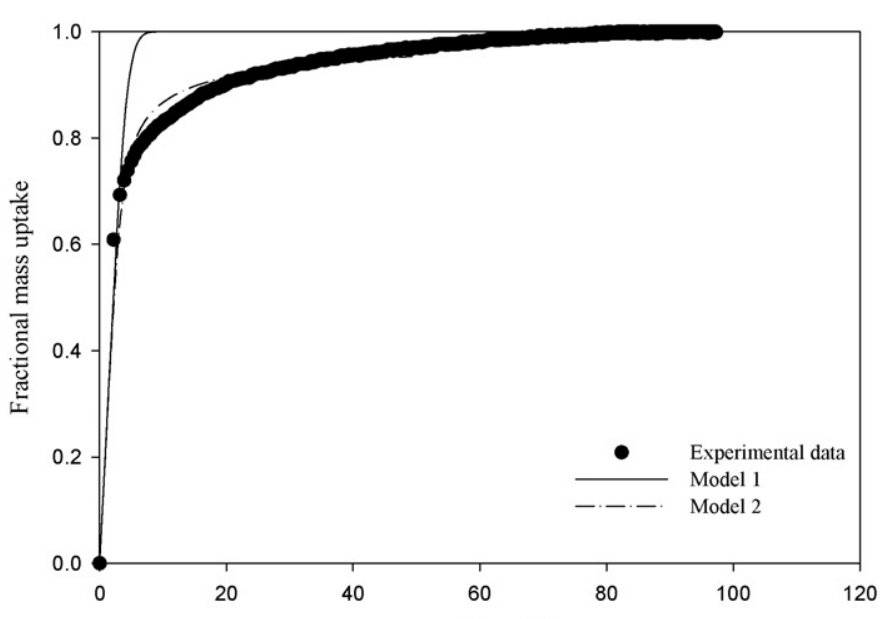

(a)

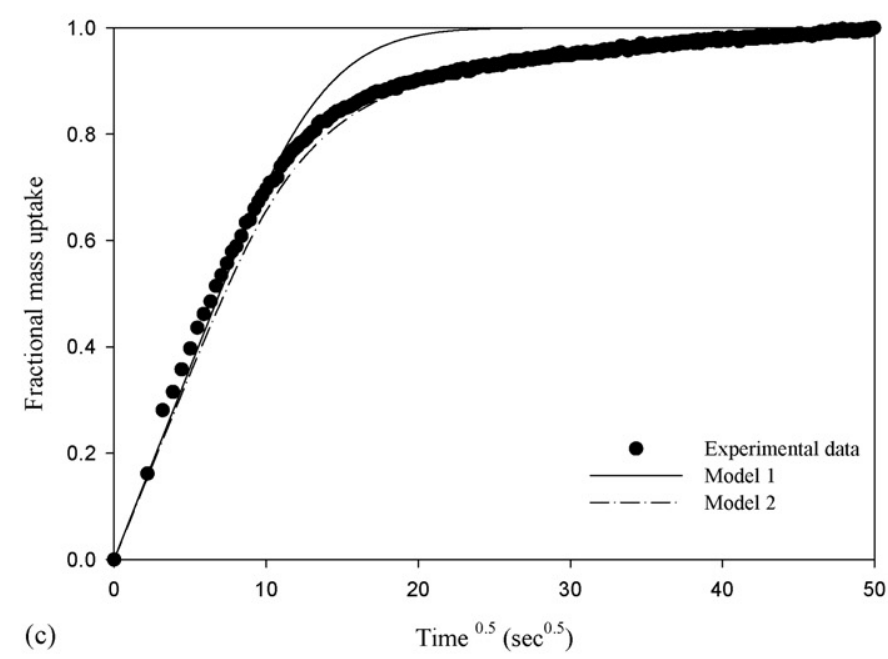

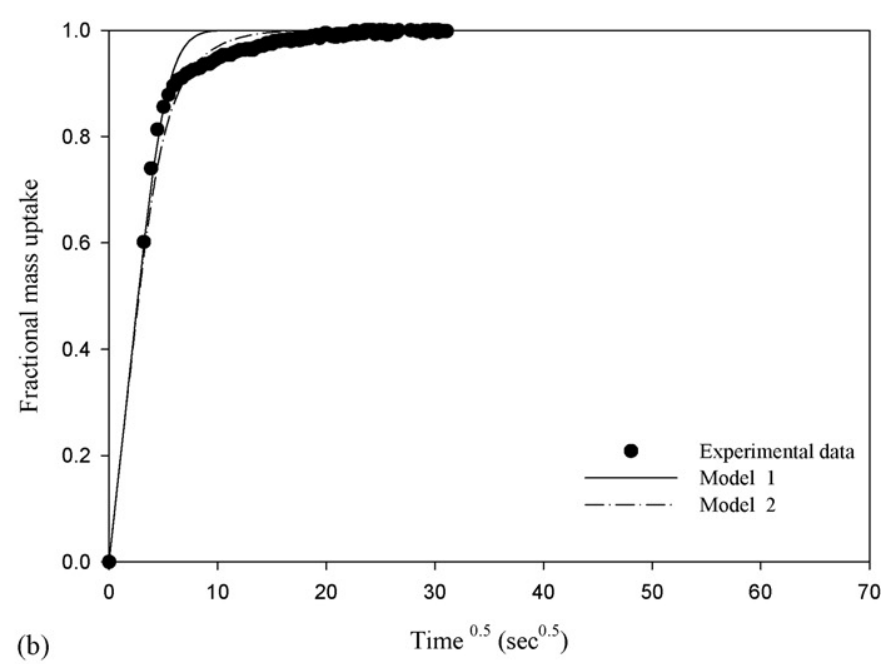

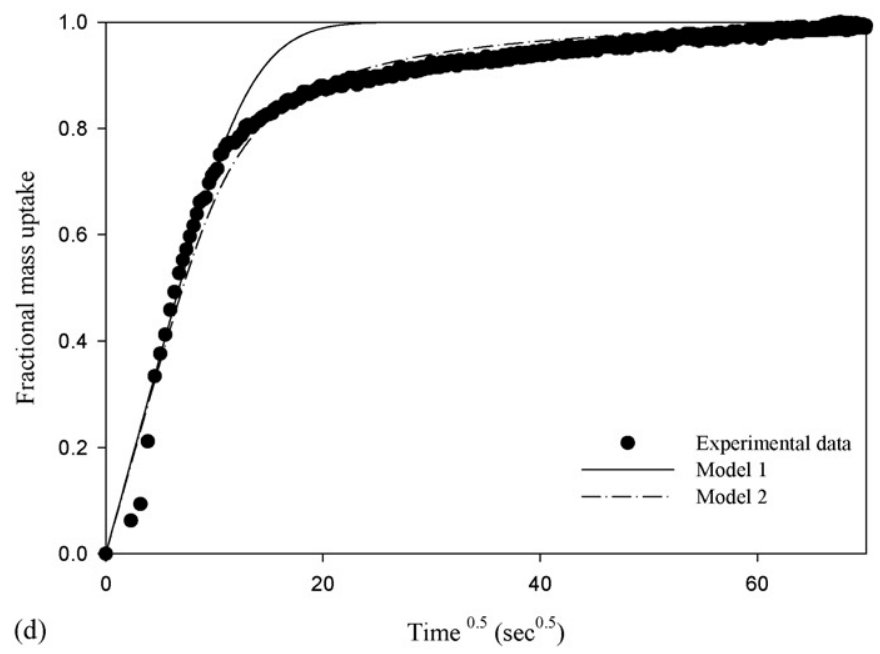

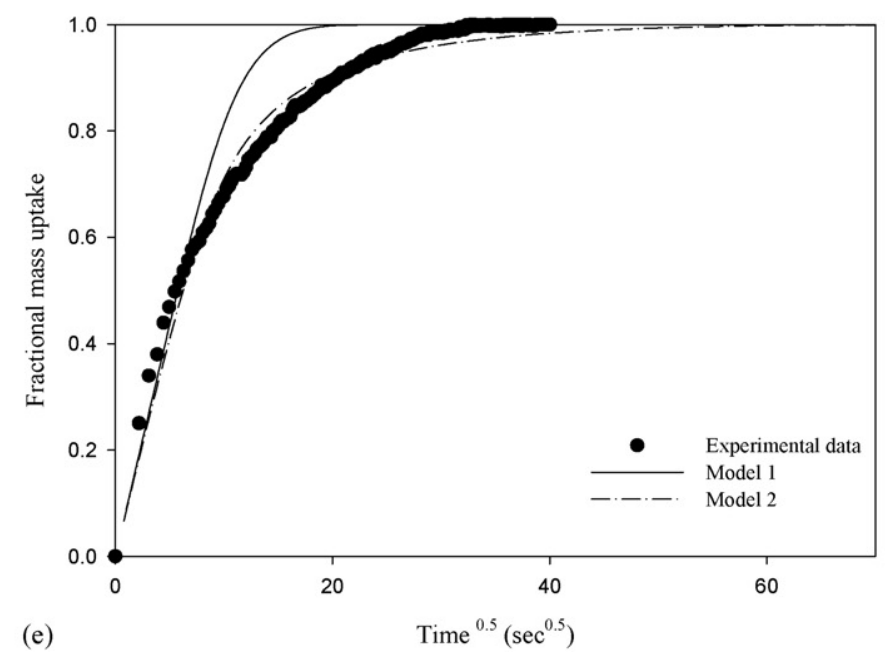

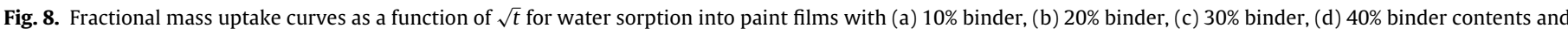

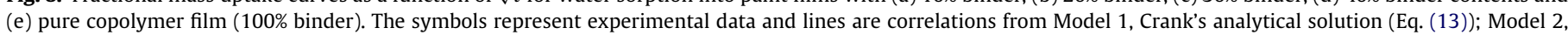
numerical model (Eqs. (10) and (11)).

pure copolymer. The mean cluster size defines the mean number of water molecules in excess of the mean water concentration in the neighbourhood of a given water molecule [18]. The large increase in the MCS with the volume fraction of water also shows a strong ten- dency for water to form cluster in the pure copolymer. In fact, large value of $k_{s}\left(k_{s}=4.372\right)$ compared to $k_{p}$ value $\left(k_{p}=0.00361\right)$ indicates that mutual interactions between water molecules are much more important than the interaction between the copolymer and water 
molecules. Fig. 7 shows that water molecules also form clusters in the paint films as indicated by positive values of $G_{w w} / V_{w}$ at all water vapour activities and the extent of clustering slightly increases with decreasing binder content in the films. Water molecules tend to form clusters since water is not a good solvent for both pure copolymer and paint films and the copolymer-water interaction is weak.

\subsection{Diffusion studies}

For paint films, gravimetric sorption curves were collected at 30 and $40^{\circ} \mathrm{C}$ and the results are presented in terms of normalized mass uptake $\left(M_{I} / M_{I \infty}\right)$ as a function of $\sqrt{t}$. The experimental conditions for each experiment are listed in Table 4 . As an illustration, Fig. 8(a)-(e) show a series of sequential normalized uptake curves obtained from water sorption into the pure copolymer and paint films containing different binder contents. All uptake curves are concave with respect to the $\sqrt{t}$ axis and the initial region is linear which suggest that sorption of water vapour in the paint film follows Fickian kinetics. For each case, experimental data were correlated with two models: Model 1 corresponds to Crank's classical analytical solution (Eq. (13)) derived by assuming that penetrant diffusivity in the film is constant and polymer film does not swell while model 2 corresponds to the numerical model which takes into account polymer swelling and concentration dependency of the diffusion coefficient (Eqs. (10) and (11)). It is clear that initially both models correlate the experimental uptake curves with the same accuracy, however, at later stages of sorption, the data are best correlated with model 2 . The constant diffusivity and no swelling assumptions lead to predict faster sorption, hence, shorter equilibrium time compared with the experimental observation. The constants $\alpha_{1}$ and $\alpha_{2}$ as well as the constant diffusion coefficient, $D_{0}$, were regressed by minimizing the difference between the experimental data and model predictions from Eqs. (10), (11) and (13), respectively. The average diffusion coefficient of water in the polymer film was then calculated from the following integral:

$\bar{D}=\int_{q_{1 o}^{*}=0}^{q_{1 E}^{*}=1} D\left(q_{1}^{*}\right) d q_{1}^{*}$

The average diffusivities reported in Table 4 for different temperatures and water vapor pressures change in the range of $0.45 \times 10^{-7}$ to $46.3 \times 10^{-7} \mathrm{~cm}^{2} / \mathrm{s}$. It is expected that the diffusion characteristics of water vapor in the films are influenced by the plasticization of the matrix and the cluster formation. The results in Table 4 indicate that the plasticization effect of water becomes dominant in the films containing $40 \%$ and $30 \%$ binder, hence, the diffusivity of water increased as the water content in the films increased. On the other hand, cluster formation between water molecules is more dominant in cases where the binder content in the films is lower ( $20 \%$ and $10 \%$ ), thus, the diffusivity of water decreased with the increased sorption levels in the films. At the same water concentration levels in the films, the diffusion coefficient of water decreased significantly with the increased binder content. As seen in Table 3, the diffusion coefficient of water in initially dried films are $46.3 \times 10^{-7}, 34.2 \times 10^{-7}, 1.47 \times 10^{-7}$ and $0.45 \times 10^{-7} \mathrm{~cm}^{2} / \mathrm{s}$ for $10 \%, 20 \%, 30 \%$ and $40 \%$ binder containing films. The increase in the diffusivity is because at low binder contents, pigments cannot be wetted significantly by the binder, thus, pigment flocculation and consequently pore formation occurs which facilitates the water transport. The water vapor permeabilities of the films reported in Table 3 also show the same tendency. They are $26.97 \times 10^{-12}, 13.65 \times 10^{-12}, 1.69 \times 10^{-12}$ and $0.78 \times 10^{-12} \mathrm{~mol} / \mathrm{s} \mathrm{cm} \mathrm{kPa}$ for $10 \%, 20 \%, 30 \%$ and $40 \%$ binder containing films.
In the case of pure copolymer films, the plasticization effect becomes dominant at low water concentrations, thus, the diffusivity increased, however, further sorption of water into the film leads to a decrease in the diffusivity of water due to cluster formation between water molecules. Not only the sorption capacity but also the diffusivities of water in the pure copolymer film at $30^{\circ} \mathrm{C}$ were found to be close to the values determined in the paint film containing $40 \%$ binder. This result is consistent with our previous finding which has shown that water vapor permeabilities of pure copolymer film and the paint film with $40 \%$ binder content are similar which are $0.73 \times 10^{-12}$ and $0.78 \times 10^{-12} \mathrm{~mol} / \mathrm{s} \mathrm{cm} \mathrm{kPa}$, respectively [13]. The diffusion coefficient of water vapor in pure copolymer films increased with the temperature due to a decrease in the apparent activation energy.

\section{Conclusion}

In this study, sorption isotherms and diffusivity of water in four different types of waterborne acrylic based paint films were determined with a gravimetric sorption technique. Similar measurements were also carried out in the films prepared from the binder of the paint (methylmethacrylate-co-butylacrylate copolymer) in order to compare the water transport properties of these films. Sorption results reveal that solubility of water decreases with the decreased binder content in the paint films. Water sorption isotherms in the paint films can be correlated with the Flory Huggins theory. In the case of water sorption into the pure copolymer films, the data are best correlated with ENSIC model. Predictions have shown that water forms clusters both in the paint and pure copolymer films. Degree of clustering and the change of mean cluster size with sorption appears to be larger in pure copolymer films. Kinetic studies indicate that water diffusion in both paint and pure copolymer films exhibit Fickian-type transport. The diffusion characteristics of water vapor in the films are influenced by the plasticization of the matrix and the cluster formation. The results indicate that binder content in the paint films significantly influences the water transport, hence, barrier properties of the films. Among all paint samples studied, the one containing $40 \%$ binder shows the best barrier property against water similar to the barrier properties of pure copolymer film.

In most studies, the swelling of the paint film as a result of water sorption is neglected, the diffusion coefficient of water is usually regarded as constant and calculated from the initial linear portion of the experimental uptake curve. This study has clearly shown that the sorption model including the concentration dependence of the diffusivity and the dimensional change of the film correlates the data much better than the classical model which neglects these factors. Thus, it seems appropriate to suggest that the utilization of simplified analytical solution may lead to errors in the estimation of diffusivities. Furthermore, it is suggested that the numerical model used in this study can form a basis to determine the concentration dependency of the diffusivity in the paint films from gravimetric sorption data.

\section{Acknowledgments}

The authors would like to thank TUBITAK (Scientific and Technical Research Council of TURKEY) and Izmir Institute of Technology for the financial support through Grants MiSAG144 and 1999 MÜH04/2001 MÜH 16. We also gratefully acknowledge Organik Kimya A.S. and Akril Kimya A.S. for providing the pure binder material and paint samples. 


\section{References}

[1] E.P.M. van Westing, G.M. Ferrari, J.H.W. de Wit, Corrosion Science 36 (1994) 957.

[2] V.B. Mišković-Stanković, D.M. Dražić, Z. Kačarević-Popović, Corrosion Science 38 (1996) 1513

[3] C. Pérez, A. Collazo, M. Izquierdo, P. Merino, X.R. Nóvoa, Progress in Organic Coatings 37 (1999) 169.

[4] C. Pérez, A. Collazo, M. Izquierdo, P. Merino, X.R. Nóvoa, Progress in Organic Coatings 36 (1999) 102.

[5] P.C. Inane, C.M. Garcia, A. Ruvolo, Journal of Coatings Technology 75 (2003) 29.

[6] B. Liu, Y. Li, H. Lin, C.N. Cao, Corrosion 59 (2003) 817.

[7] G. Lendvay-Győrik, T. Pajkossy, B. Lengyel, Progress in Organic Coatings 59 (2007) 95.

[8] L.V.S. Philippe, S.B. Lyon, C. Sammon, J. Yarwood, Corrosion Science 50 (2008) 887.

[9] E.L.J. Goossens, A.J.J. van der Zanden, W.H. van der Spoel, Progress in Organic Coatings 49 (2004) 270.

[10] E.L.J. Goossens, A.J.J. van der Zanden, H.L.M. Wijen, W.H. van der Spoel, Progress in Organic Coatings 48 (2003) 112
[11] A.J.J. van der Zanden, E.L.J. Goossens, Chemical Engineering Science 58 (2003) 1521.

[12] S. Alsoy, J.L. Duda, AIChE Journal 48 (2002) 1849.

[13] O. Topcuoglu, S.A. Altinkaya, D. Balkose, Progress in Organic Coatings 56 (2006) 269.

[14] G.A. Truskey, F. Yuan, D.F. Katz, Transport Phenomena in Biological Systems, Prentice Hall, New Jersey, 2004.

[15] J. Crank, The Mathematics of Diffusion, 2nd ed., Oxford University Press, Oxford, 1975.

[16] J.A. Barrie, in: J. Crank, G.S. Park (Eds.), Diffusion in Polymers, Academic Press, London, 1968.

[17] L. Perrin, Q.T. Nguyen, D. Sacco, P. Lochon, Polymer International 42 (1997) 9.

[18] O. Rodriguez, F. Fornasiero, A. Arce, C.J. Radke, J.M. Prausnitz, Polymer 44 (2003) 6323.

[19] J.M. Prausnitz, R.N. Lichtenthaler, E.G. Azevedo, Molecular Dynamics of Fluid Phase Equilibria, 2nd ed., Prentice Hall Inc., New Jersey, 1986.

[20] K.A. Schult, D.R. Paul, Journal of Polymer Science Part B: Polymer Physics 34 (1996) 2805. 